\title{
Pasting Properties of Various Waxy Rice Flours: Effect of $\alpha$-amylase activity, protein, and amylopectin
}

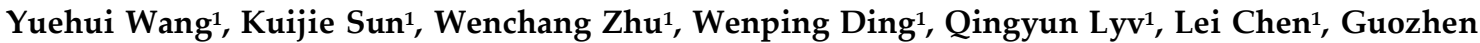 \\ Wang1, Kun Zhuang1, Xi Chen ${ }^{1 *}$ \\ ${ }^{1}$ Key Laboratory of Bulk Grain and Oil Deep Processing Ministry of Education, School of Food Science and Engineering, Wuhan \\ Polytechnic University, Wuhan 430023, China. \\ Correspondence should be addressed to Xi Chen; e-mail: xchen@whpu.edu.cn
}

\begin{abstract}
Waxy rice is one of the most popular traditional crops served as a staple food in China. In this study, the effect of different factors including $\alpha$-amylase activity, protein, and amylopectin structure on the pasting properties of four waxy rice varieties were investigated. Rice flours treated with $\mathrm{AgNO}_{3}$ solution, DL-dithiothreitol (DTT) or protease, suggested that both $\alpha$-amylase activity and protein significantly decrease the pasting viscosity of waxy rice flours. Chain length distribution of amylopectin as measured by high performance ion exchange chromatography (HPAEC-PAD) showed that starch with higher ratio of short chain leading to a higher pasting viscosity. X-Ray diffractograms showed that the crystal type of all the four varieties of rice starches were characteristic A-type. Relative crystallinity of each rice starch was further calculated, and a higher crystallization resulted in a higher viscosity. Our study would provide a fundamental knowledge of the relationship between different factors and waxy starch pasting properties, as well as be a reference for controlling the quality of waxy rice starch-based food.
\end{abstract}

Keywords: waxy rice starch; $\alpha$-amylase; protein; amylopectin structure 


\section{Introduction}

Waxy (or glutinous) rice (Oryza sativa L.) has a long history of being cultivated and consumed in China. Traditional Chinese waxy rice-based foods include waxy rice ball, sweet green rice ball, waxy rice cake, Nuomici, Zongzi, etc.,[1] while in the modern food industry, waxy rice is usually processed into flour before usage and consumption. The physicochemical properties of the flours especially pasting properties guarantees the appealing texture of its food products.

Many factors could influence the pasting properties of waxy rice flour, such as the endogenous $\alpha$ amylase activity, proteins, and amylopectin structure [2]. There is an agreement that endogenous $\alpha$ amylase strongly impact the pasting properties of grain flours, $[3,4]$ and the in-activation of $\alpha$-amylase by adding Silver nitrate $\left(\mathrm{AgNO}_{3}\right)$ would enhance their viscosities [4]. However for proteins, there were controversial opinions [5]. Some reported that protein increased the pasting viscosity of rice flour [6, 7], others only discovered a weak correlation between proteins and rice flour [8]. Thus, more evidence should be documented in this area. Most starches consist of 20-30\% amylose and 70-80\% amylopectin, ratios vary with the botanical sources.[9] Comparing with that, waxy rice starch contains almost $100 \%$ of amylopectin that makes it crucial in its pasting characteristics [10-12], and therefore could serve as a good model to study the relationship between amylopectin structure and its pasting properties.[2] The molecular structure of amylopectin has the same basic structure as amylose, while considerably contains more $\alpha-(1,6)$-branches and shorter chains [13] that contributing to a three-dimensional complex structure. The chain-length distributions was reported to be a main controller of its pasting properties.[14] Although there're a number of studies regarding the relationship between amylopectin chain-length distribution and pasting properties, conflicting results were obtained. Some studies reported that higher proportion of shorter chain (DP 6-12) and lower proportion of long chain (DP > 37) indicating a higher peak pasting viscosity [15-17], while others found out that peak viscosity is positively correlated with the amount of amylopectin medium and long chains.[18] In this aspect, more studies should be focused on chain-length distribution and pasting viscosity in the future.

To our knowledge, the effect of $\alpha$-amylase activity, protein, and amylopectin structure were often investigated separately in most studies regarding the relationship between waxy rice starch and its pasting properties. In the present study, the effect of the three factors on the pasting properties were studied at the same time, with emphasis on the underlying reason for the difference of pasting properties among various cultivars from North and South China. Our study would not only provide a fundamental knowledge of the association between various factors and waxy starch pasting properties, but also be a reference for quality control of waxy rice starch-based food.

\section{Materials and Methods}

\subsection{Materials}

Four representative high production waxy rice cultivars from North or South China were selected: Vietnam indica (VI); Jiangxi indica (JI); Anhui japonica (AJ); Dongbei japonica (DJ). Rice samples were provided by Henan Huangguo Grains Industry Co., Ltd. (Henan, China). All reagents and chemicals were of analytical grade and obtained from Sinopharm Chemical Reagent Co., Ltd. (Shanghai, China) or Sigma-Aldrich (Bornem, Belgium) unless specified otherwise.

\subsection{Preparation of Waxy Rice Flour}

Waxy rice flour was prepared by a wet-milling method according to Tong et al.[19] Briefly, rice samples were cleaned and washed three times to remove impurities, and then soaked into distilled water at room temperature for $4 \mathrm{hrs}$ before put into a colloid mill (JM-L50, Shanghai Nuoni Light Industrial Machinery Co. Ltd, Shanghai). The rice slurry was then vacuum filtered and dried in an airdry oven at $40^{\circ} \mathrm{C}$ for $12 \mathrm{hrs}$, and then grounded, passed through a 100-mesh screen to obtain the dried rice flour. The flour samples were packed and stored at $4{ }^{\circ} \mathrm{C}$ for further use. 


\subsection{Composition Analyses of Waxy Rice Flour}

Starch content was determined by a Futura continuous flow analyzer (AMS Alliance, France). Crude protein content was estimated by determination of Nitrogen $(\mathrm{N})$ content using a Vario EL element analyzer (Elementar, German) and then $N$ values were converted to protein content by $N \times 5.95$. Crude ash, crude lipid, and moisture content were determined by Chinese Standard GB/T5009.4-2010, GB/T5009.6-2003 and GB/T5009.3-2010 respectively. All the components were converted to dry base contents based on water content.

\subsection{Rice Starch Isolation}

Waxy rice starch was isolated by alkaline method according to Mu et al.[20] with slight modifications. The rice flour was soaked into $0.085 \mathrm{~mol} / \mathrm{L} \mathrm{NaOH}$ solution with a material to liquid ratio of $1: 5 \mathrm{~g} / \mathrm{ml}$, stirred at $40{ }^{\circ} \mathrm{C}$ for $4 \mathrm{hrs}$, and then centrifuged at $3000 \mathrm{r} / \mathrm{min}$ for $15 \mathrm{~min}$. The dark yellow supernatant was scraped from the sediment and discarded, and then the sediment was washed with distilled water and adjusted to $\mathrm{pH} 7.0$ with $1 \mathrm{M} \mathrm{HCl}$ before centrifuged for $15 \mathrm{~min}$. The procedure was repeated twice until the sediment was pure white, and then lyophilized to dryness to obtain high purity rice starch.

\subsection{Determination of $\alpha$-amylase Activity}

A colorimetric method as described by Hesheng $\mathrm{Li}$ [21] was hired to determine $\alpha$-amylase activity. Maltose was used for standard curve, and 3,5-dinitrosalicylic acid (DNS) was used as coloring agent. $\mathrm{OD}$ values were measured at $540 \mathrm{~nm}$. The $\alpha$-amylase activity of each waxy rice flours was calculated according to OD values and the maltose standard curve and expressed as micro grams per gram per minute $(\mathrm{mg} /(\mathrm{g} \cdot \mathrm{min}))$.

\subsection{RVA analysis}

The pasting properties of the selected four rice flours with and without $0.085 \mathrm{~g} / \mathrm{L} \mathrm{AgNO}$ or 0.77 g/L DL-dithiothreitol (DTT) solution or protease were tested in triplicate with a Rapid Visco Analyzer (RVA) (Newport Scientific, Narrabeen, Australia), using std1 temperature programming according to ICC standard No. 162 and AACC66-21. In addition, pasting properties of rice starches were also tested.

\subsection{X-Ray diffraction}

X-Ray diffractograms were obtained with a D/Max-2200 X-Ray diffractometer (Righku Denki Co., Tokyo, Japan) with $\mathrm{Cu} K \alpha$ radiation at $40 \mathrm{kV}$ and $50 \mathrm{~mA}$. The diffractograms were scanned between $5^{\circ}$ and $60^{\circ}(2 \theta)$ at a rate of $1.2^{\circ} / \mathrm{min}$. Relative crystallinity was estimated by the ratio of the peak areas to the total diffractogram area as described by Chen et al.[22]

\subsection{Chain-length distribution of amylopectin}

The branch chain-length distribution of amylopectin was measured by high performance ion exchange chromatography (HPAEC) equipped with a pulse amperometric detector (PAD) as described by A. Blennow [23]. Starch samples were gelatinized and then debranched by isoamylase. The debranched amylopectin solution was filtered through a PVDF membrane filter $(0.45 \mu \mathrm{m})$ before injected into the HPAEC-PAD system. Eluents A ( $0.5 \mathrm{M}$ sodium hydroxide), B ( $0.5 \mathrm{M}$ sodium acetate), and $C$ (distilled water) were operated at a flow rate of $1 \mathrm{~mL} / \mathrm{min}$. The separation gradient of eluents was as follows: $0 \mathrm{~min}, 20 \% \mathrm{~A}, 10 \% \mathrm{~B}$, and $70 \% \mathrm{C} ; 0-40 \mathrm{~min}$, linear gradient to $20 \% \mathrm{~A}$ and $80 \% \mathrm{~B}$.

\subsection{Statistic analysis}

Each experiment was done in triplicate. Results were expressed as average \pm standard deviation (SD). Analysis of one-way ANOVA with Duncan's multiple range test and Pearson's correlation were performed using SPSS software (version 19.0, Statistical Package for the Social Sciences Inc., Chicago, USA). A value of $\mathrm{p}<0.05$ was considered to be statistically significant. 


\section{Results and Discussion}

\subsection{Composition of Rice Flours}

Total starch, protein, lipid, moisture, and ash contents of the four varieties were listed in Table 1. Moisture content was higher in japonica rice than that of indica rice. Japonica rice contains more starch than indica, especially Dongbei japonica (DJ). The protein and starch contents of the four varieties were around $7 \%$ and $90 \%$ respectively, which was in accordance with other findings [24, 25]. Both protein and lipid contents were the highest in Jiangxi indica (JI) among the four cultivars. Ash content in DJ was the highest followed by JI.

Table 1: Composition of the flours from the four waxy rice cultivars*

\begin{tabular}{cccccc}
\hline $\begin{array}{c}\text { Rice } \\
\text { cultivar }\end{array}$ & Water\% & Starch\% & Protein $\%$ & Lipid\% & Ash\% \\
\hline VI & $12.11 \pm 0.12^{\mathrm{a}}$ & $88.24 \pm 0.49^{\mathrm{a}}$ & $6.99 \pm 0.00^{\mathrm{b}}$ & $0.89 \pm 0.04^{\mathrm{b}}$ & $0.27 \pm 0.02^{\mathrm{a}}$ \\
JI & $11.26 \pm 0.08^{\mathrm{a}}$ & $89.64 \pm 0.43^{\mathrm{b}}$ & $7.66 \pm 0.01^{\mathrm{d}}$ & $1.22 \pm 0.08^{\mathrm{c}}$ & $0.68 \pm 0.03^{\mathrm{c}}$ \\
AJ & $13.67 \pm 0.10^{\mathrm{b}}$ & $88.26 \pm 0.38^{\mathrm{a}}$ & $7.52 \pm 0.00^{\mathrm{c}}$ & $0.76 \pm 0.10^{\mathrm{a}}$ & $0.42 \pm 0.02^{\mathrm{b}}$ \\
DJ & $14.64 \pm 0.06^{\mathrm{c}}$ & $90.84 \pm 0.17^{\mathrm{c}}$ & $6.43 \pm 0.00^{\mathrm{a}}$ & $0.87 \pm 0.07^{\mathrm{b}}$ & $0.75 \pm 0.02^{\mathrm{d}}$ \\
\hline
\end{tabular}

*Values are mean \pm standard deviation $(n=3)$. Means that do not share the same letter in a column are significantly different at $\mathrm{p}<0.05$. VI: Vietnam indica; JI: Jiangxi indica; AJ: Anhui japonica; DJ: Dongbei japonica

\subsection{Effect of a-amylase on Pasting Properties of Waxy Rice Flours}

$\mathrm{AgNO}_{3}$ could serve as an inhibitor for $\alpha$-amylase to verify the presence of endogenous amylase activity in flours and characterize the pasting properties of flours without enzyme interference.[2] In this study, the pasting properties of different waxy rice flours treated with $\mathrm{AgNO}_{3}$ were tested, and the flours treated with distilled water were used as control. Results were shown in Figure 1 and summarized in Table 2 . In the meantime, $\alpha$-amylase activity was measured and results are shown in Table 3.
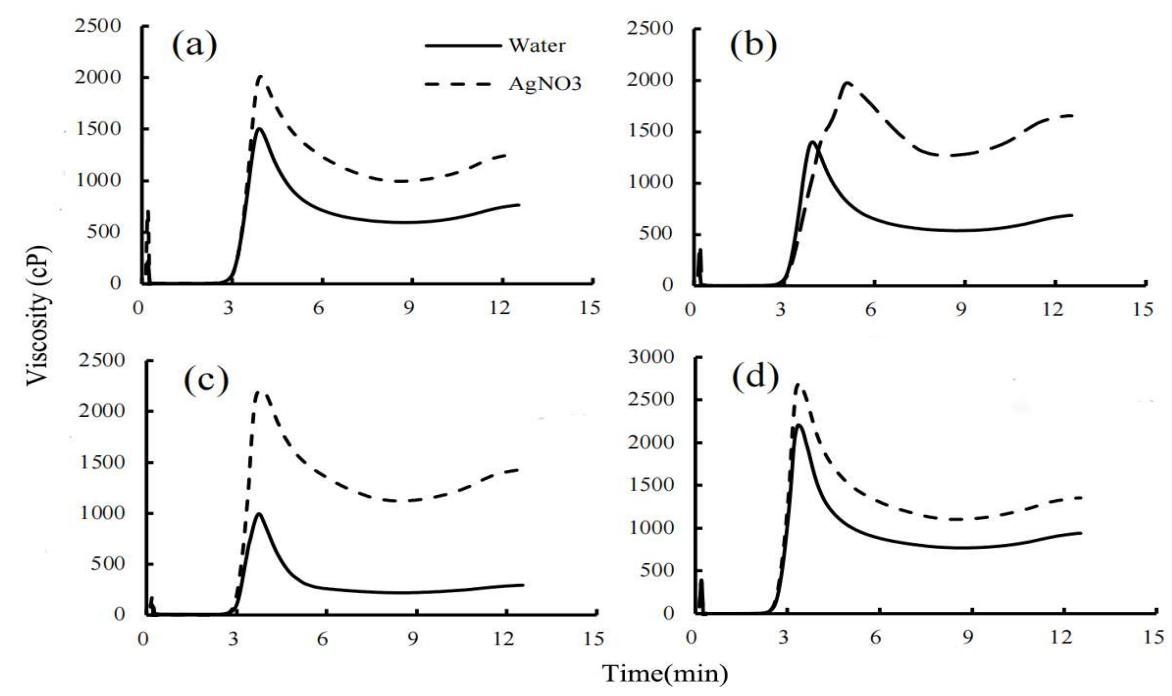

Figure 1: Pasting curves of flours of four waxy rice cultivars treated with distilled water or $\mathrm{AgNO}_{3}$. (a) Vietnam indica (VI); (b) Jiangxi indica (JI); (c) Anhui japonica (AJ); (d) Dongbei japonica (DJ). 
Table 2: Pasting properties of various varieties of waxy rice flours*

\begin{tabular}{|c|c|c|c|c|}
\hline \multirow{2}{*}{ Rice Variety } & \multicolumn{3}{|c|}{ Viscosity (cP) } & \multirow[b]{2}{*}{ Setback } \\
\hline & Peak & Trough & Final & \\
\hline \multicolumn{5}{|c|}{ Waxy rice flours with distilled water } \\
\hline VI & $1503 \pm 82^{b}$ & $595 \pm 65^{b}$ & $746 \pm 76^{b}$ & $151 \pm 12^{b}$ \\
\hline JI & $1400 \pm 88^{b}$ & $536 \pm 35^{b}$ & $685 \pm 35^{b}$ & $149 \pm 15^{b}$ \\
\hline $\mathrm{AJ}$ & $994 \pm 62^{a}$ & $218 \pm 23^{a}$ & $293 \pm 89^{a}$ & $75 \pm 6^{\mathrm{a}}$ \\
\hline DJ & $2203 \pm 89 c$ & $769 \pm 78^{c}$ & $940 \pm 56^{c}$ & $171 \pm 13^{b}$ \\
\hline \multicolumn{5}{|c|}{ Waxy rice flours with $\mathrm{AgNO}_{3}$} \\
\hline VI & $2011 \pm 102^{\mathrm{ab}}$ & $995 \pm 87^{a}$ & $1260 \pm 121^{\mathrm{a}}$ & $265 \pm 23^{a}$ \\
\hline JI & $1975 \pm 102^{a}$ & $1268 \pm 117^{b}$ & $1654 \pm 106^{b}$ & $386 \pm 27 b$ \\
\hline $\mathrm{AJ}$ & $2216 \pm 132^{b}$ & $1121 \pm 89 \mathrm{ab}$ & $1428 \pm 103^{a}$ & $307 \pm 21^{a}$ \\
\hline DJ & $2704 \pm 127 c$ & $982 \pm 98^{a}$ & $1354 \pm 107 a$ & $372 \pm 28^{\mathrm{b}}$ \\
\hline
\end{tabular}

*Values are mean \pm standard deviation $(n=3)$. VI: Vietnam indica; JI: Jiangxi indica; AJ: Anhui japonica; DJ: Dongbei japonica

The peak, trough, and final viscosity of all the four varieties showed an increase with $\mathrm{AgNO}_{3}$ treatment when comparing with water treatment (Figure 1 and Table 2), suggesting that the endogenous $\alpha$-amylase of the four varieties decreased their viscosities. Meanwhile, the largest increasement of viscosity was showed in AJ (Figure 1), which was found to possess the highest $\alpha$ amylase activity among the four varieties (Table 3), indicating that higher active of $\alpha$-amylase may contribute to lower viscosity of AJ. This result was in accordance with the findings of Zhu et al. [2], Noda et al. [4], and Cheng et al. [26], since $\alpha$-amylase catalyses the endo-hydrolysis of $\alpha-1,4$ glucan bonds and play a major role during the degradation of native starch granules. Waxy rice flours seem to be sensitive to $\alpha$-amylase breakdown, even a few internal cleavages of amylopectin would lead to a reduction in molecular weight and result in a lower viscosity.[3] The apparent difference in viscosities observed in the flours with and without enzyme inactivation underscores the effect of amylase activity on the waxy rice flour pasting profile.

Table 3: Alpha-amylase activity of various waxy rice flours*

\begin{tabular}{ccccc}
\hline Rice Variety & VI & JI & AJ & DJ \\
\hline $\begin{array}{c}\alpha \text {-Amylase activity } \\
{[\mathrm{mg} /(\mathrm{g} \cdot \mathrm{min})]}\end{array}$ & $11.3 \pm 0.1^{\mathrm{c}}$ & $10.9 \pm 0.2^{\mathrm{b}}$ & $12.8 \pm 0.3^{\mathrm{d}}$ & $9.7 \pm 0.2^{\mathrm{a}}$ \\
\hline
\end{tabular}

*Values are mean \pm standard deviation $(n=3)$. VI: Vietnam indica; JI: Jiangxi indica; AJ: Anhui japonica; DJ: Dongbei japonica

To investigate the relationship between $\alpha$-amylase activity, composition contents of flours and pasting viscosities, correlation coefficients were further calculated. As shown in Table 4, significance inverse correlation was observed between $\alpha$-amylase activity and pasting viscosities including peak, trough, and final viscosities, which confirmed the effect of $\alpha$-amylase activity on the pasting viscosity of waxy rice flours. However, no significant correlation was found between composition contents and pasting viscosities, indicating that the compositions of the waxy rice flour seemed not associated with its gelatinization characteristics. 
Table 4: Correlation coefficient (r) between $\alpha$-amylase activity or composition contents and pasting viscosities

\begin{tabular}{cccc}
\hline & \multicolumn{3}{c}{ Viscosity (cP) } \\
\cline { 2 - 4 } & Peak & Trough & Final \\
\hline$\alpha$-amylase activity & $-0.958^{*}$ & $-0.967^{*}$ & $-0.957^{*}$ \\
Starch\% & 0.834 & 0.762 & 0.697 \\
Protein\% & -0.873 & -0.763 & -0.743 \\
Lipid\% & 0.926 & 0.724 & 0.702 \\
Ash\% & 0.572 & 0.459 & 0.428 \\
\hline
\end{tabular}

${ }^{*} \mathrm{p}<0.05$

\subsection{Effect of Protein on Pasting Properties of Waxy Rice Flours}

To investigate the effect of protein on pasting properties of waxy rice flours, DTT or protease were used in our study. Results were showed in Figure 2 and 3. For DTT treatment, all the flours showed a decrease in their viscosities, among which the peak viscosity of JI decreased most, followed by AJ and DJ. The starch granules break down easily in the absence of rigidity caused by disulfide-bound protein polymers that surrounding the native granules [27]. DTT could cleave di-sulfide bonds between cysteines in the proteins and diminish the carbohydrate binding activity of starch with proteins [28], leading to an increase of starch be released from the proteins. The released starch would correspondently hydrolyzed by the endogenous $\alpha$-amylase that further resulted in the decrease of viscosity in waxy rice flours [28]. According to Figure 2, the decrease of viscosities varied in the four varieties, indicating that other than protein, amylase activities or other factors may play an additional role. The present study did not find obvious associations between $\alpha$-amylase activities and the varied decrease of viscosities in the DTT treated flours (Table 3 and Figure 2), which seemed not in consistent with the findings of Zhu et al.[2] as they reported that $\alpha$-amylase activity positively influence the decrease of viscosity in the DTT treatment. Thus, to clear out the influence of amylase activity and further study the effect of proteins on flours pasting properties, the flours were treated with and without protease in the presence of $\mathrm{AgNO}_{3}$, results were showed in Figure 3. The pasting viscosities was increased in the four varieties in the protease treated group (Figure 3(a)) when comparing with non-protease treated group (Figure 3(b)), indicating that protein had an inhibitory effect on the pasting properties of waxy rice flour. DTT or protease, either by disulfide bond disruption or protein removal, was reported to share similar effects on the pasting properties of waxy rice flours [6].

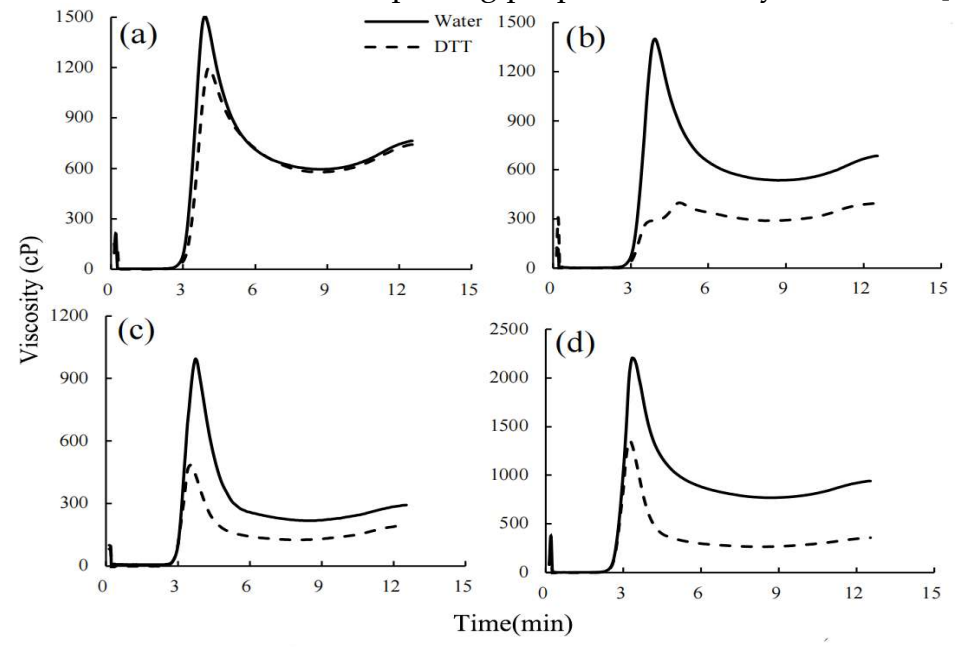

Figure 2: Pasting curves of flours of four waxy rice cultivars treated with distilled water or DTT. (a) Vietnam indica (VI); (b) Jiangxi indica (JI); (c) Anhui japonica (AJ); (d) Dongbei japonica (DJ). 


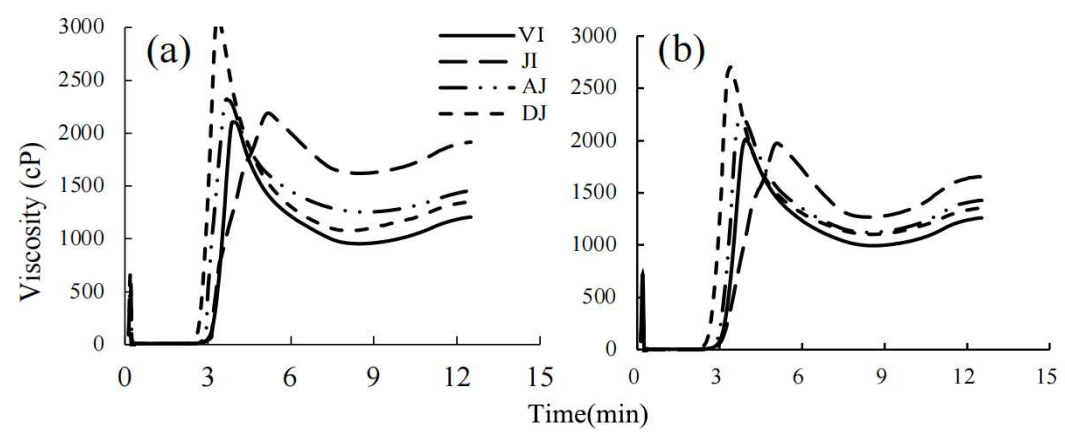

Figure 3: Pasting curves of $\mathrm{AgNO}_{3}$ treated waxy rice flours with (a) or without protease (b). Vietnam indica (VI); Jiangxi indica (JI); Anhui japonica (AJ); Dongbei japonica (DJ).

\subsection{Effect of Starch and its Amylopectin Structure on Pasting Properties of Waxy Rice Flours}

Different waxy rice starches showed different pasting properties (Table 5). DJ possessed the highest peak viscosity, followed by AJ. The peak viscosity was significantly higher in japonica than indica rice $(p>0.05)$. Although not statistically significant, the trough viscosity was also higher in japonica than indica rice. For final viscosities and setback, JI was the highest while VI was the lowest. The difference of pasting properties among various waxy rice starches might due to the difference in their structures [15, 29-31], such as their branch chain length and the degree of crystallinity in the amylopectin. In our study, the branch chain-length distribution of amylopectin was measured by high performance ion exchange chromatography (HPAEC), meanwhile the degree of crystallinity was estimated by the ratio of the peak areas to the total diffractogram area as described by Chen et al.[22].

Table 5: Pasting properties of waxy rice starches*

\begin{tabular}{ccccc}
\hline \multirow{2}{*}{ Rice Varieties } & \multicolumn{4}{c}{ Viscosity (cP) } \\
\cline { 2 - 5 } & Peak & Trough & Final & Setback \\
\hline Pure rice starch & & & \\
\hline VI & $2089 \pm 73^{\mathrm{a}}$ & $982 \pm 67^{\mathrm{a}}$ & $1315 \pm 45^{\mathrm{a}}$ & $333 \pm 17^{\mathrm{a}}$ \\
JI & $2076 \pm 84^{\mathrm{a}}$ & $919 \pm 88^{\mathrm{a}}$ & $1280 \pm 68^{\mathrm{b}}$ & $361 \pm 36^{\mathrm{a}}$ \\
AJ & $2286 \pm 95^{\mathrm{b}}$ & $1028 \pm 64^{\mathrm{a}}$ & $1391 \pm 53^{\mathrm{a}}$ & $363 \pm 25^{\mathrm{a}}$ \\
DJ & $2820 \pm 124^{\mathrm{c}}$ & $1020 \pm 45^{\mathrm{a}}$ & $1355 \pm 63^{\mathrm{a}}$ & $335 \pm 23^{\mathrm{a}}$ \\
\hline
\end{tabular}

*Values are mean \pm standard deviation $(\mathrm{n}=3)$. VI: Vietnam indica; JI: Jiangxi indica; AJ: Anhui japonica; DJ: Dongbei japonica

The X-ray diffraction patterns were presented in Figure 4, and relative crystallinity of the four waxy rice starches were summarized in Table 6 . The waxy rice starches displayed the typical A-type polymorphic form with an unresolved peak at $17^{\circ}$ and $18^{\circ}$ and individual peaks at $15^{\circ}, 20^{\circ}$, and $23^{\circ}$ in the X-ray diffractograms (Figure 4). The relative crystallinity (Table 6) calculated from X-ray diffraction pattern ranged from $34.5 \%$ (JI) to $38.9 \%$ (DJ), which was slightly lower than previously reported [32, 33]. This might due to different cultivars of waxy rice were used. Despite that, the amylopectin chain length distribution also had an impact on relative crystallinity [34]. According to Table 6, Japonica rice possessed higher relative crystallinity than indica rice. The relative crystallinity of DJ was the highest meanwhile JI was the lowest. The relative crystallinity of each starches increased with the amounts of DP 6-12 (Table 6), because short chains $(\mathrm{DP}<10)$ in amylopectin resulted in a decrease in the stability of 
double helix that leading to a lower value of relatively crystallinity [32]. Moreover, the relative amounts of DP 13-24 increased with relative crystallinity confirmed that the semi-crystalline nature of starch was ascribed to amylopectin double helices in the crystalline lamellae of the starch granule structure, which was in line with the studies of G. E. Vanderputte et al [34]. A higher degree of crystallization in waxy starch probably reflects more closely packed crystal structures [3] which may lead to higher viscosities (Table 5).

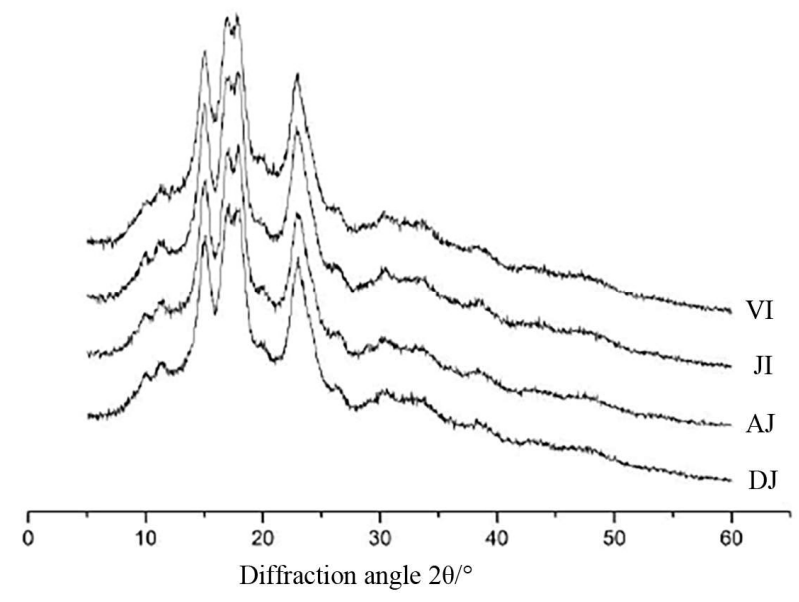

Figure 4: X-ray diffraction patterns of various waxy rice starches. VI: Vietnam indica; JI: Jiangxi indica; AJ: Anhui japonica; DJ: Dongbei japonica

Table 6: Branch chain length distributions of amylopectin in waxy rice starches*

\begin{tabular}{cccccc}
\hline \multirow{2}{*}{$\begin{array}{c}\text { Rice } \\
\text { Variety }\end{array}$} & $\begin{array}{c}\text { The relative } \\
\text { crystallinity (\%) }\end{array}$ & \multicolumn{3}{c}{ Chain length distribution of amylopectin } & (\%) \\
\cline { 3 - 6 } & 35.13 & $29.37 \pm 0.35^{\mathrm{b}}$ & $50.61 \pm 0.08^{\mathrm{a}}$ & $11.58 \pm 0.16^{\mathrm{c}}$ & $8.08 \pm 0.28^{\mathrm{b}}$ \\
VI & 34.52 & $27.60 \pm 0.23^{\mathrm{a}}$ & $50.22 \pm 0.03^{\mathrm{a}}$ & $12.12 \pm 0.29^{\mathrm{d}}$ & $8.23 \pm 0.09^{\mathrm{b}}$ \\
JI & 37.54 & $30.38 \pm 0.33^{\mathrm{c}}$ & $52.39 \pm 0.25^{\mathrm{b}}$ & $9.20 \pm 0.09^{\mathrm{a}}$ & $8.03 \pm 0.00^{\mathrm{b}}$ \\
AJ & 38.92 & $31.68 \pm 0.41^{\mathrm{d}}$ & $52.05 \pm 0.21^{\mathrm{b}}$ & $10.66 \pm 0.05^{\mathrm{b}}$ & $7.44 \pm 0.15^{\mathrm{a}}$ \\
\hline
\end{tabular}

*Values are mean \pm standard deviation $(n=3)$. VI: Vietnam indica; JI: Jiangxi indica; AJ: Anhui japonica; DJ: Dongbei japonica

HPAEC-PAD chromatograms of branch chain-length distribution of amylopectin were showed in Figure 5. The lengths of the amylopectin chains were reported to have a major impact on rice starch properties [35]. The chain of amylopectin was classified into A chain (DP 6-12), B1 chain (DP 13-24), B2 chain (DP 25-36), B3+ chain (DP > 37) according to previous research [34-36]. The pattern of area percentages of amylopectin chains showed a bimodal distribution, DPs of the four varieties of waxy rice starches were ranged from 6 to 80 (Figure 5). All the four varieties displayed two distinct groups with DP 6-33 and DP 34-62 in the chromatogram were observed. Specifically, there were very few short chains of DP6 and a gradual increase in chains of DP 7-9, with a maximum peak at DP 12 and a shoulder at DP 15 in the DP 6-33 group, meanwhile the DP 34-62 group showed a peak at DP 40. These results were in accordance with previous research that A type starches had its first peak at DP 12-14 and second peak at DP 41-51 [9]. Among the four varieties, JI possessed the lowest proportion of DP 6-12 chains $(27.60 \pm 0.23 \%)$, indicating that there were fewer short chain A chains in JI starch. DJ possessed the 
largest DP 6-12 (A chains) and lowest DP > 37 (B3+ chains) proportions respectively, suggesting the average chain length of DJ was shorter. These results were in accordance with the findings that indica rice possessed more long chains (DP>37) than japonica rice [16]. Waxy rice starch with higher proportion of shorter chain (DP 6-12) and lower proportion of long chain (DP > 37), for example DJ, indicating a higher peak pasting viscosity (Table 5 \& 6) [15-17].

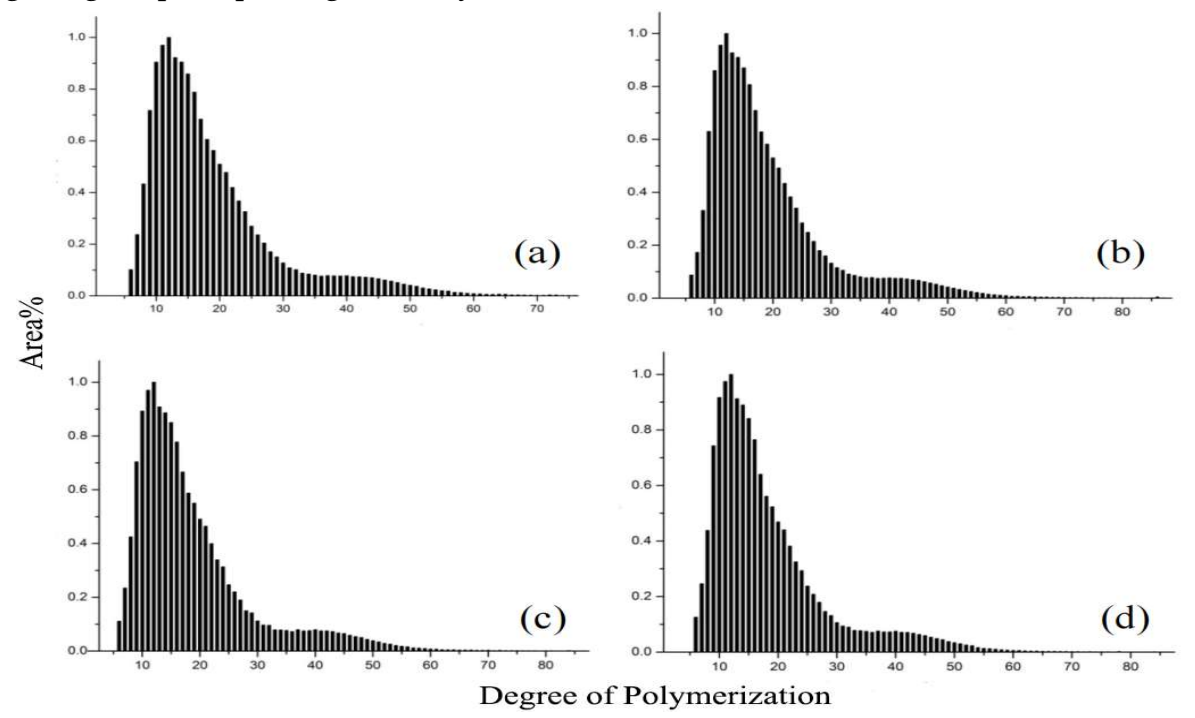

Figure 5: Chain length distribution of waxy rice starch amylopectins. (a) Vietnam indica (VI); (b) Jiangxi indica (JI); (c) Anhui japonica (AJ); (d) Dongbei japonica (DJ).

\section{Conclusions}

In conclusion, the present study showed that the pasting viscosities of the four waxy rice flours could be increased by adding $\mathrm{AgNO}_{3}$, while decreased by their own protein. In addition, the crystal type of the four varieties of rice starches were characteristic A-type. Higher degree of crystallization with more short chain in the amylopectin structure would leads to higher viscosities. Taken together, the rice protein, $\alpha$-amylase activity, and amylopectin structure were the major causes of the different pasting properties among various varieties of waxy rice flours.

Funding: This research was funded by National grain industry public welfare project "new technology for preserving the qualities and reducing the mass losses of grain and oil during storage" (Grant number 201413007).

Author Contributions: Conceptualization, Y.W., W.D., and Q.L.; Methodology, W.Z., K.Z., and Q.L.; Validation, W.D.; Formal Analysis, Y.W. and X.C.; Investigation, W.Z.; Data Curation, K.Z. and G.W.; Writing - Original Draft Preparation, Y.W., W.Z, and K.S.; Writing - Review \& Editing, Y.W. and X.C.; Visualization, K.S and L.C.; Supervision, Y.W. and X.C.; Funding Acquisition, W.D.

Conflicts of Interest: The authors declare that there is no conflict of interest regarding the publication of this paper. 


\section{References}

1. Guo, L., et al., The effects of wheat amylose ratios on the structural and physicochemical properties of waxy rice starch using branching enzyme and glucoamylase. Food Hydrocolloids, 2021. 113: p. 106410.

2. Zhu, L.-J., et al., Underlying reasons for waxy rice flours having different pasting properties. Food Chemistry, 2010. 120(1): p. 94-100.

3. Abdel-Aal, E., et al., Physicochemical and structural characteristics of flours and starches from waxy and nonwaxy wheats. Cereal Chemistry, 2002. 79(3): p. 458-464.

4. $\quad$ Noda, T., et al., The Pasting Properties of Flour and Starch in Wheat Grain Damaged by Ealpha;Amylase. Food Science and Technology Research, 2003. 9(4): p. 387-391.

5. Bhattacharya, K.R., Physicochemical basis of eating quality of rice. Cereal Foods World, 2009. 54(1): p. 18-28.

6. Xie, L., et al., Impact of proteins on pasting and cooking properties of waxy and non-waxy rice. Journal of Cereal Science - J CEREAL SCI, 2008. 47: p. 372-379.

7. Martin, M. and M.A. Fitzgerald, Proteins in Rice Grains Influence Cooking Properties! Journal of Cereal Science, 2002. 36(3): p. 285-294.

8. Lyon, B.G., et al., Effects of Degree of Milling, Drying Condition, and Final Moisture Content on Sensory Texture of Cooked Rice. Cereal Chemistry, 1999. 76(1): p. 56-62.

9. Jane, J., et al., Effects of Amylopectin Branch Chain Length and Amylose Content on the Gelatinization and Pasting Properties of Starch. Cereal Chemistry, 1999. 76(5): p. 629-637.

10. Ding, W., et al., Effect of ozone treatment on physicochemical properties of waxy rice flour and waxy rice starch. International Journal of Food Science \& Technology, 2015. 50(3): p. 744-749.

11. Li, H., et al., The importance of amylose and amylopectin fine structure for textural properties of cooked rice grains. Food Chemistry, 2016. 196: p. 702-711.

12. Dutta, H., C.L. Mahanta, and V. Singh, Changes in the properties of rice varieties with different amylose content on dry heat parboiling. Journal of Cereal Science, 2015. 65: p. 227-235.

13. Bertoft, E., Understanding Starch Structure: Recent Progress. Agronomy, 2017. 7(3).

14. Li, C., et al., Parameterizing starch chain-length distributions for structure-property relations. Carbohydrate Polymers, 2020. 241: p. 116390.

15. Oh, S. and M. Shin, Physicochemical properties and molecular structures of Korean waxy rice starches. Food Science and Biotechnology, 2015. 24: p. 791-798.

16. Huang, Y.-C. and H.-M. Lai, Characteristics of the starch fine structure and pasting properties of waxy rice during storage. Food Chemistry, 2014. 152: p. 432-439.

17. Juliano, B.O., R.M. Villareal, and L. Baños, Varietal Differences in Physicochemical Properties of Waxy Rice Starch. Starch - Stärke, 1987. 39(9): p. 298-301.

18. Li, C., et al., A combined action of amylose and amylopectin fine molecular structures in determining the starch pasting and retrogradation property. International Journal of Biological Macromolecules, 2020. 164: p. 2717-2725.

19. Tong, L., et al., Preparation of fresh rice noodles using rice prepared by tempering moisture and semidry milling method and determination of its quality. Transactions of the Chinese Society of Agricultural Engineering, 2014. 30(23): p. 332-338.

20. Mu, H., et al., Study on the Separation of High Purity Glutinous Rice Starch. Food Research and Development, 2009. 30(1): p. 91-94.

21. Li, H., Principles and Techniques of Plant Physiological and Biochemical Experiments. 2000, Beijing: Higher Education Press.

22. Chen, F., et al., Research progress of determination crystallinity of starch granular by X-ray diffraction. Science and Technology of Food Industry, 2010. 31(1): p. 432-435.

23. Blennow, A., et al., Starch molecular structure and phosphorylation investigated by a combined chromatographic and chemometric approach. Carbohydrate Polymers, 2000. 41: p. 163-174.

24. Li, Z., et al., Impact of binding interaction characteristics on physicochemical, structural, and rheological properties of waxy rice flour. Food Chemistry, 2018. 266: p. 551-556. 
25. Kim, J.-w., et al. Protein Content and Composition of Waxy Rice Grains. 2013.

26. Cheng, K., et al., The Relationship between Physicochemical Property and Pasting Curve of Rice Starch. Journal of the Chinese Cereals and Oils Association, 2006. 21(06): p. 4-8.

27. Hamaker, B.R. and V.K. Griffin, Effect of disulfide bond-containing protein on rice starch gelatinization and pasting. Cereal chemistry., 1993. 70(4): p. 377-380.

28. Alliegro, M., Effects of Dithiothreitol on Protein Activity Unrelated to Thiol-Disulfide Exchange: For Consideration in the Analysis of Protein Function with Cleland's Reagent. Analytical biochemistry, 2000. 282: p. 102-6.

29. Kowittaya, C. and N. Lumdubwong, Molecular weight, chain profile of rice amylopectin and starch pasting properties. Carbohydrate Polymers, 2014. 108: p. 216-223.

30. Wang, Y.-J. and L. Wang, Structures of Four Waxy Rice Starches in Relation to Thermal, Pasting, and Textural Properties. Cereal Chemistry, 2002. 79(2): p. 252-256.

31. Kim, J.-O., W.-S. Kim, and M.-S. Shin, A Comparative Study on Retrogradation of Rice Starch Gels by DSC, X-Ray and $\alpha$-Amylase Methods. Starch - Stärke, 1997. 49(2): p. 71-75.

32. You, S.-Y., et al., Impact of molecular and crystalline structures on in vitro digestibility of waxy rice starches. Carbohydrate Polymers, 2014. 112: p. 729-735.

33. Shi, M.-m. and Q.-y. Gao, Physicochemical properties, structure and in vitro digestion of resistant starch from waxy rice starch. Carbohydrate Polymers, 2011. 84(3): p. 1151-1157.

34. Vandeputte, G.E., et al., Rice starches. I. Structural aspects provide insight into crystallinity characteristics and gelatinisation behaviour of granular starch. Journal of Cereal Science, 2003. 38(1): p. 43-52.

35. Noosuk, P., et al., Relationship between Viscoelastic Properties and Starch Structure in Rice from Thailand. Starch/Stärke, 2005. 57(12): p. 587-598.

36. Hanashiro, I., J.-i. Abe, and S. Hizukuri, A period distribution of the chain length of amylopectin as revealed by high-performance anion-exchange chromatography. Carbohydrate Research, 1996. 283(10): p. 151-159. 